\title{
(E)-5-Fenil-N-(2-tiyenilmetilen)-1,3,4-tiyadiazol-2-amin'in Hirshfeld Yüzey Analizi ve Teorik Hesaplamaları
}

\author{
Gonca Özdemir Tarı ${ }^{*}$, Güneş Demirtaş ${ }^{2}$ \\ 1*Vezirköprü Vocational School, Ondokuz Mayıs University, 55900, Samsun, Turkey, (ORCID: 0000-0001-5919-1778), gozdemir@omu.edu.tr \\ ${ }^{2}$ Department of Physics, Faculty of Arts and Sciences, Ondokuz Mayıs University, 55139 Samsun, Turkey, (ORCID:0000-0001-9953-4026), gunesd@omu.edu.tr
}

(International Conference on Design, Research and Development (RDCONF) 2021 - 15-18 December 2021)

(DOI: $10.31590 /$ ejosat.1039524)

ATIF/REFERENCE: Özdemir Tarı, G., Demirtaş, G. (2021). (E)-5-Fenil-N-(2-tiyenilmetilen)-1,3,4-tiyadiazol-2-amin'in Hirshfeld Yüzey Analizi ve Teorik Hesaplamaları. Avrupa Bilim ve Teknoloji Dergisi, (32), 761-769.

$\ddot{\mathbf{O} z}$

(E)-5-Fenil-N-(2-tiyenilmetilen)-1,3,4-tiyadiazol-2-amin, $\left(\mathrm{C}_{13} \mathrm{H}_{9} \mathrm{~N}_{3} \mathrm{~S}_{2}\right)$, molekülü daha önce yapılan bir çalı̧mada sentezlenmiş ve $\mathrm{x}$ ışını kırınımı analizi ile karakterize edilmiştir (Demirtaş vd., 2009). Bu mevcut çalışmada adı geçen bileşiğin geometrik parametreleri YFK/B3LYP/6-311++G(d,p) baz seti kullanılarak hesaplanmış ve hesaplanan geometrik parametrelerle deneysel değerler (Demirtaş vd., 2009) karşılaş̧ırılmıştır. Deneysel sonuçlarla teorik hesaplamalar arasındaki karşılaştırmada, YFK/B3LYP/6-311++G(d,p) ile elde edilen değerlerin deneysel veri ile iyi bir uyum içerisinde olduğu belirlenmiştir. Bu çalışmalara ek olarak, teorik metotlar kullanılarak çözücü ortamda bileşik için Moleküler Elektrostatik Potansiyel, Sınır Orbitalleri (HOMO-LUMO) analizi hesaplanmıştır. Bundan başka moleküller arası etkileşimi tespit etmek için Hirshfeld yüzey analizi gerçekleştirilmiştir.

Anahtar Kelimeler: Hirsfeld Yüzey Analizi, Teorik Hesaplamalar, Yoğunluk Fonksiyon Teorisi

\section{Hirshfeld Surface Analysis and Theoretical Calculations of the (E)-5-Phenyl-N-(2-thienylmethylene)-1,3,4-thiadiazole-2-amine}

\begin{abstract}
In a previously study, (E)-5-Phenyl-N-(2-thienylmethylene)-1,3,4-thiadiazole-2-amine, $\left(\mathrm{C}_{13} \mathrm{H}_{9} \mathrm{~N}_{3} \mathrm{~S}_{2}\right)$, molecule had been synthesized and characterized by x-ray diffraction analysis (Demirtaş et al., 2009). In this current study, geometric parameters of the title compound were calculated by using DFT/B3LYP/6-311++G(d,p) basis set and the experimental (Demirtaş et al., 2009) values with the calculated geometric parameters were compared. The comparison between the theoretical calculations and experimental results revealed that the parameters obtained by DFT/B3LYP/6-311++G(d,p) were in good agreement with the experimental data. In addition to these studies, molecular electrostatic potential and frontier orbitals (HOMO-LUMO) analysis for the title compound were computed in the solvent media by using theoretical methods. Furthermore, Hirshfeld surface analysis were performed to determine intermolecular interactions.
\end{abstract}

Keywords: Hirsfeld Surface Analysis, Theoretical Calculations, Density Functional Theory

\footnotetext{
* Sorumlu Yazar: gozdemir@omu.edu.tr
} 


\section{Giriş}

Heterosiklik bileşikler, kükürt, oksijen veya nitrojen ile birlikte en az bir karbon atomu içeren halkalı bileşikler olup tiyadiazoller ise kükürt ve azot atomu içeren beş üyeli bir halka sistemidir (Shihab, 2021) ve antibakteriyel ve antifungal özelliklere sahip aktif gruplardandır (Çırdaklı, 2018). Bu bileşiklerin endüstriyel uygulamalarından dolayı sentezi çok önemli olmakla birlikte, antiviral ve antiinflamatuar özelliklerinden dolayı da kükürt ve azot içeren bu bileşikler birçok çalışmanın ve çalışmacının odağı haline gelmiştir (French, 2005; Rossi vd., 2013; Hagar vd., 2020; Cordell, 2008) ki literatüre bakıldığında 1,3,4-tiyadiazol halkasının biyolojik aktivitelerdeki etkin rolünden kaynaklı yaygın olarak kullanıldığı görülmektedir.

$\mathrm{X}$-1şını kırınımı yöntemiyle yapısı daha önce aydınlatılmış olan (E)-5-Fenil-N-(2-tiyenillmetilen)-1,3,4-tiyadiazol-2-amin (Demirtaş vd., 2009) moleküler yapısının teorik çalışmaları Yoğunluk Fonksiyonel Kuramı (YFK) ile belirlenmiş ve sonuçları X-1şınları ile karşılaştırılmıştır. X-1şını kırınımından elde edilen atomik koordinatlar teorik hesaplamalar için başlangıç verisi olarak kullanılmıştır. Çalışmanın amacı farklı çözücü ortamlarından elde edilen geometrik parametrelerin, moleküle ait elektronik ve kimyasal sonuçların X-1şını verileriyle uyumunu karşılaştırıp tartışmaktır. Molekül içi etkileşimlerin ayrıntılı açıklaması için ise Hirsfeld Yüzey Analizi yapılmış ve sonuçlar paylaşılmıştır.

\section{Materyal ve Metot}

Kuantum mekaniği nesnelerin konum ve momentum bilgilerini kullanarak, çeşitli kuvvet alanları altında nasıl hareket etmeleri gerektiğini bulmaya çalışır. Gelişimi ile birlikte bilim insanları sayesinde çok çeşitli bakış açıları geliştirilmiş ve birçok alanda başarılı bir şekilde uygulanmıştır. Kuantum fikirleri üzerine geliştirilen yapı analizleri bir molekülün sahip olduğu tüm fiziksel ve kimyasal özellikleri bize sunmakla birlikte malzeme biliminden elektroniğe, antropolojiden astrofiziğe, moleküler biyolojiden modern tıbba, uzay araştırmalarından metalurjiye kadar bütün alanlarda önemli buluşlara imza atmıştır ve atmaya devam edecektir (Özdemir Tarı, 2013). Hesaplamaların tümü Gaussian 03W (Frisch vd., 2004) programı, YFK'nın Lee-YangParr korelasyon enerjili 3 parametreli Becke karma modeli olan B3LYP/6-311++G(d,p) baz seti kullanılarak yapılmıştır. Sonuçlarda çözücü etkisini gözlemleyebilmek için gaz faza ilave olarak tüm hesaplamaları üç farklı çözücü (etanol, dimetilsülfoksit, su) ortamında da gerçekleştirerek, sonuçlar karşılaştırılmıştır. Moleküler yapıya ait görselleştirmeler GaussView (Dennigton, 2007) arayüz programı ile yapılmıştır. Öncelikli olarak moleküler yapının hem gaz hem de farklı çözücü ortamlarında optimizasyonu sonucu en kararlı yapıları elde edilmiş ve diğer tüm çalışmalar bu optimize yapılar üzerinden ilerlemiştir. Molekülün sınır orbitalleri, HOMOLUMO değerleri, Moleküler Elektrostatik Potansiyel (MEP) haritaları ve yük analizleri yine farklı çözücü ortamlar için belirlenip karşılaştırmaları yapılmıştır.

Tablo 1. Moleküle ait bazı geometrik parametrelerin deneysel ve teorik olarak elde edilen değerleri.

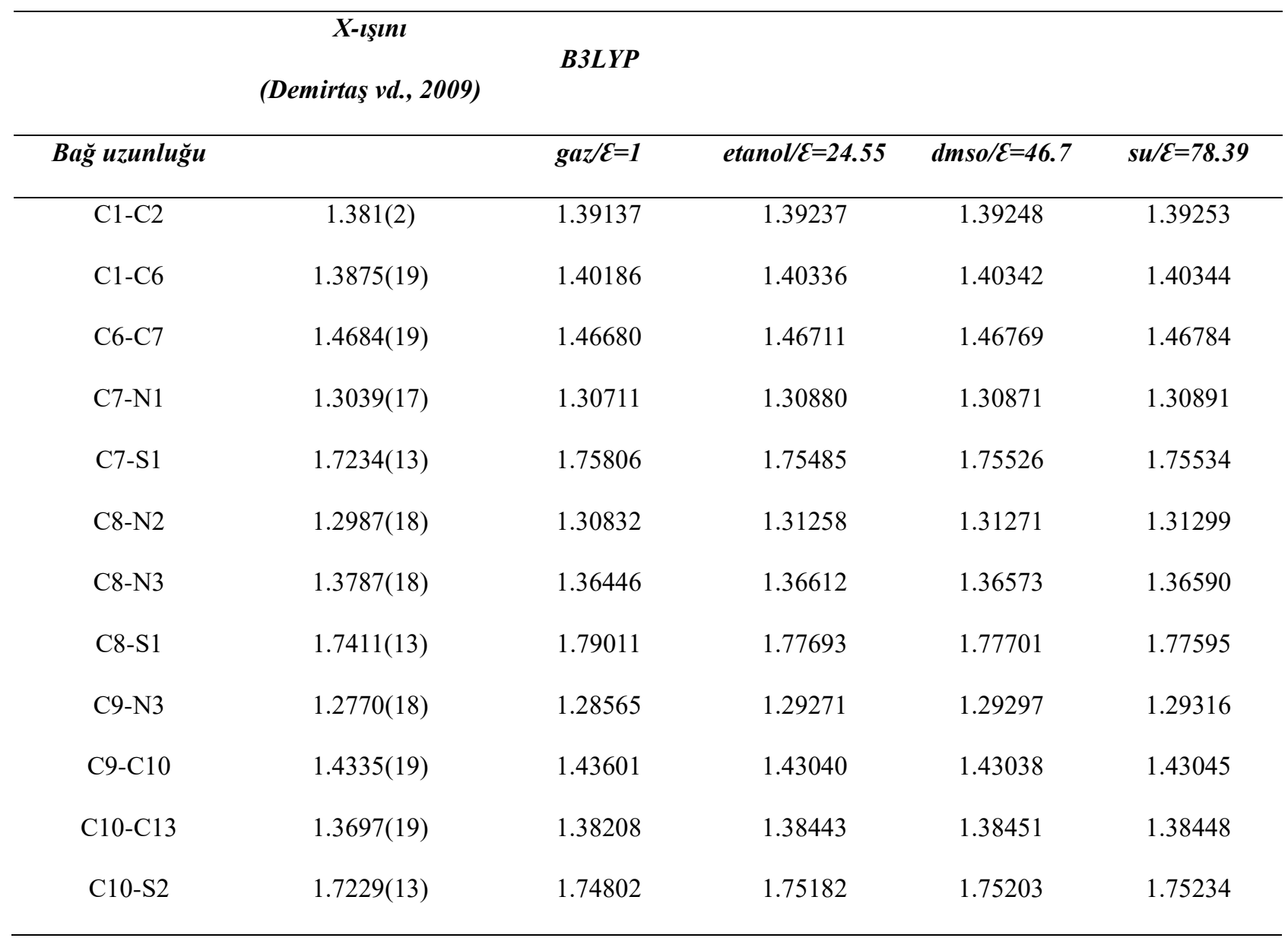


European Journal of Science and Technology

\begin{tabular}{|c|c|c|c|c|c|}
\hline C11-S2 & $1.6993(17)$ & 1.72577 & 1.72602 & 1.72616 & 1.72622 \\
\hline N1-N2 & $1.3696(19)$ & 1.34940 & 1.35696 & 1.35658 & 1.35660 \\
\hline Maks. Fark & & 0.04901 & 0.06742 & 0.03186 & 0.03485 \\
\hline Кок & & 0.0210 & 0.0261 & 0.0316 & 0.0193 \\
\hline \multicolumn{6}{|l|}{ Băğ açısı } \\
\hline $\mathrm{C} 2-\mathrm{C} 1-\mathrm{C} 6$ & $120.44(14)$ & 120.51110 & 120.43243 & 120.44386 & 120.43935 \\
\hline $\mathrm{N} 2-\mathrm{C} 8-\mathrm{S} 1$ & $113.44(11)$ & 112.22983 & 112.25699 & 112.23612 & 112.27138 \\
\hline N3-C8-S1 & $127.22(10)$ & 126.11855 & 126.63566 & 126.78295 & 126.89467 \\
\hline N3-C9-C10 & $120.78(12)$ & 122.43145 & 122.82105 & 122.70732 & 122.60830 \\
\hline $\mathrm{C} 13-\mathrm{C} 10-\mathrm{C} 9$ & $128.09(12)$ & 126.77338 & 126.08531 & 126.13154 & 126.17085 \\
\hline $\mathrm{C} 13-\mathrm{C} 10-\mathrm{S} 2$ & $110.88(10)$ & 111.01616 & 110.91561 & 110.90704 & 110.89614 \\
\hline $\mathrm{C} 12-\mathrm{C} 11-\mathrm{S} 2$ & $112.30(12)$ & 112.68716 & 112.64129 & 112.62384 & 112.62153 \\
\hline $\mathrm{C} 9-\mathrm{C} 10-\mathrm{S} 2$ & $120.94(10)$ & 122.21046 & 122.99903 & 122.96141 & 122.93301 \\
\hline $\mathrm{C} 11-\mathrm{C} 12-\mathrm{C} 13$ & $112.73(14)$ & 112.22202 & 112.36704 & 112.38021 & 112.38403 \\
\hline C1-C6-C7 & $121.70(12)$ & 121.89573 & 121.53080 & 121.42317 & 121.40050 \\
\hline $\mathrm{N} 1-\mathrm{C} 7-\mathrm{C} 6$ & $122.79(12)$ & 123.30280 & 123.84375 & 123.82242 & 123.80324 \\
\hline N1-C7-S1 & $113.62(11)$ & 112.96601 & 112.91465 & 112.86535 & 112.86590 \\
\hline C6-C7-S1 & $123.58(9)$ & 123.73119 & 123.24139 & 123.31197 & 123.33074 \\
\hline $\mathrm{N} 2-\mathrm{C} 8-\mathrm{N} 3$ & $119.33(12)$ & 121.65163 & 121.10734 & 120.98053 & 120.83332 \\
\hline C9-N3-C8 & $120.94(12)$ & 122.16600 & 121.41682 & 121.52970 & 121.58589 \\
\hline C7-S1-C8 & $87.01(6)$ & 86.22929 & 86.73176 & 86.74941 & 86.75280 \\
\hline Maks. Fark & & 2.32163 & 2.05903 & 2.02141 & 1.99301 \\
\hline КОK & & 1.0439 & 1.1076 & 1.0732 & 1.0363 \\
\hline \multicolumn{6}{|l|}{ Burulma açısı } \\
\hline C2-C1-C6-C7 & $-179.40(13)$ & 179.99763 & -179.99564 & -179.98909 & 179.98351 \\
\hline C1-C6-C7-N1 & $-175.17(14)$ & -179.90953 & -173.91102 & -173.60215 & -173.80991 \\
\hline C5-C6-C7-N1 & $5.7(2)$ & 0.08802 & 6.04744 & 6.36805 & 6.12999 \\
\hline N3-C9-C10-C13 & $175.89(14)$ & 179.98897 & 179.74150 & 179.79255 & 179.95481 \\
\hline N3-C9-C10-S2 & $-0.24(19)$ & -0.01965 & -0.16597 & -0.18883 & -0.07930 \\
\hline C6-C7-N1-N2 & $-179.04(13)$ & 179.99695 & -179.87819 & -179.82424 & -179.89967 \\
\hline N3-C8-N2-N1 & $-178.89(13)$ & 179.99959 & -179.74558 & -179.96352 & 179.99487 \\
\hline
\end{tabular}




\begin{tabular}{cccccc}
\hline S1-C8-N2-N1 & $0.45(19)$ & -0.01247 & -1.74461 & 0.25010 & 0.26387 \\
N2-C8-N3-C9 & $176.50(15)$ & -179.83269 & 178.29885 & 179.10568 & 178.64125 \\
S1-C8-N3-C9 & $-2.7(2)$ & 0.18113 & -1.74461 & -1.14121 & -1.67002 \\
N3-C8-S1-C7 & $178.84(13)$ & 179.99706 & 179.78369 & -179.97700 & -179.93522 \\
\hline
\end{tabular}

\section{Araştırma Sonuçları ve Tartışma}

\subsection{Optimize Yapı}

Şekil 1. a'da x-1şını kırınımından elde edilen (Demirtaş vd., 2009) yapıya ait Ortep-3 şekli ve moleküle ait optimize görünümleri Şekil.1. b'de verilmiştir. Farklı çözücü ortamına ait hesaplamalarından elde edilen geometrik veriler Tablo 1'de karşılaştırmalı olarak verilmiştir.

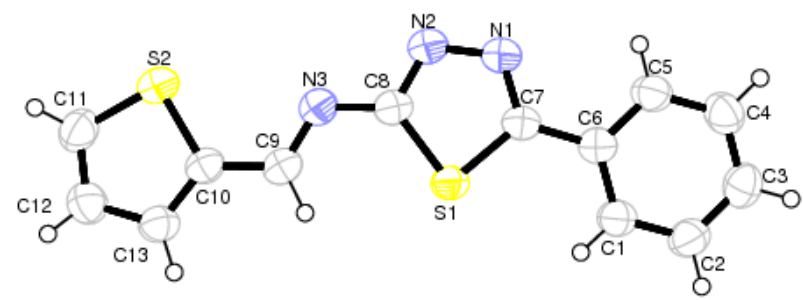

(a)

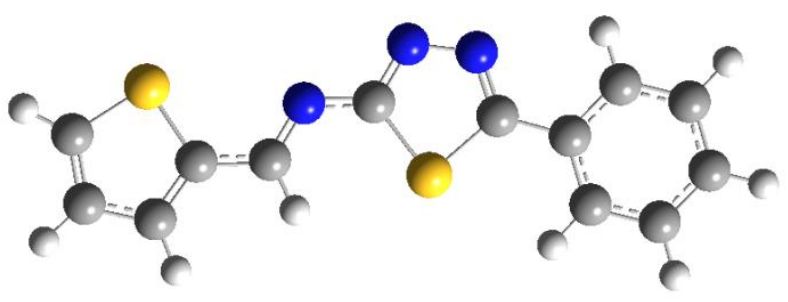

(b)

Şekil 1. (a) Molekülün \%30 olasılıklı elipsoitlerle çizilmiş ORTEP-3 diyagramı (Demirtaş vd., 2009), (b) B3LYP/6-

$311 \mathrm{G}++(\mathrm{d}, \mathrm{p})$ gaz faz için optimize şekli.

N3=C9 bağ uzunluğu 1.2770 (18) Å olup tipik çift bağ karakteri, N3-C8 bağ uzunluğu ise $1.3787 \AA$ değeriyle tek bağ karakter taşımaktadır (Demirtaş vd., 2009). Bu bağ uzunluklarını 1.2856 $\AA$ (gaz), $1.2929 \AA$ (dmso), $1.2927 \AA$ (etanol) ve $1.2931 \AA$ (su); N3-C8 tekli bağına bakıldığında ise 1.3644 (gaz), 1.3657 (dmso), 1.3661 (etanol) ve 1.3659 (su) değerleri elde edilmiştir. Tablo 1'e bakıldığında geometrik verilerin birbirleri ile uyumlu olduğu gözükmektedir. Ortamdaki çözücünün dielektrik sabiti (E) arttıkça bağ uzunluğu ve bağ açılarının genel olarak arttığı söylenilebilir. Optimize yapı (gaz) ile x-ışını kırınımından elde edilen değerler arasındaki farklılıklar ise teorik hesaplamalarda moleküler yapının gaz fazında olması ile açıklanabilir ve tüm etkileşimlerin ihmali üzerine yapılan bir hesaplama türüdür. Diğer taraftan geometrik parametrelerin deneysel parametrelerle uyumunu göstermek için kullanılan bir başka yöntem ise optimize ve deneysel yapıların hata paylarını belirlemektir. Bağ uzunluğu ve bağ açılarında bulunan deneysel değer ile teorik değer farkının maksimum olduğu değer maksimum farktır, RMSE değerleri ise molekülün tamamının hata değerleridir. Elde edilen hata değerleri sırasıyla; B3LYP/6-311G++(d,p) gaz faz için ise 0.089 , dmso için 0.103 , etanol için 0.101 ve su için 0.099 olarak bulunmuştur. Hata değerleri incelendiğinde deneysel parametrelerle en iyi uyumu sağlayan optimize yapının gaz faz ile hesaplatılan yapı olduğu ortamın polaritesi arttıkça hata değerinin arttığı gözlenmektedir. Bu değerlerde üst üste bindirme sonucunda elde edilen şekilleri (bknz Şekil 2) ve Tablo 1 'de verilen hata değerlerini destekler niteliktedir.

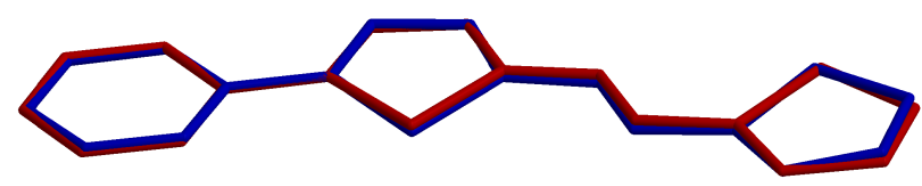

(gaz)

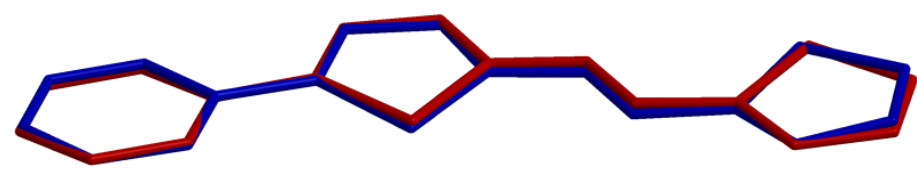

(dmso)

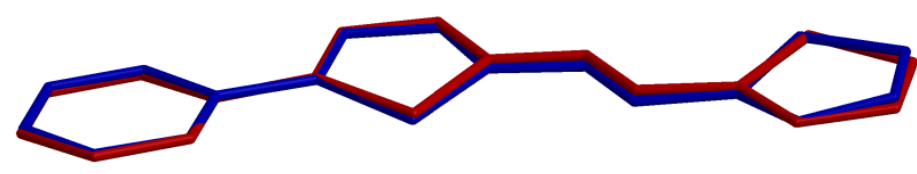

(etanol)

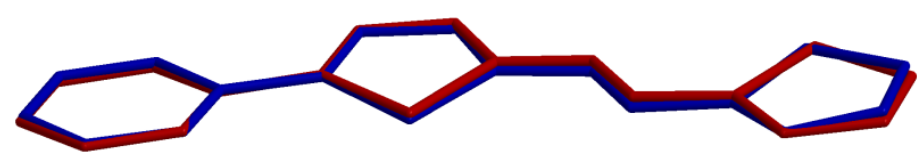

(su)

Şekil 2. Moleküle ait X-ışnı kırınımında elde edilen optimize geometrisi (mavi) ile sırasıyla gaz, dmso, etanol ve su çözücü ortamlarında elde edilen optimize geometrilerin üst üste örtüşmeleri. 


\subsection{Moleküler Elektrostatik Potansiyel}

Moleküler elektrostatik potansiyel (MEP) haritaları, atomların elektronegatifliğini ve molekül içi etkileşimlerin açıklanmasında kullanılan tanımlayıcı yöntemlerden birisi olup molekül üzerindeki atomik konumlar ve bu konumlara ait elektronik yoğunluklardan faydalanır. Elde edilen yüzey haritalarında elektronca zengin olan kısımlar kırmızı ile, elektronca zayıf olan kısımlar ise mavi olacak şekilde bu aralıkta renklendirilir. $\mathrm{Bu}$ renklendirmeler yardımıyla moleküler yüzeydeki yük dağılımları, olası elektrostatik etkileşim bölgeleri, elektrofilik ve nükleofilik bölgeler görselleştirilmiş olur ve böylelikle moleküler yapının aktif oluğu bölgeler belirlenerek gelecekte yapılması planlanan çalışmalar için yeni sentez çalışmalarının önü açılmış olacaktır. Moleküle ait MEP haritası en kararlı yapıya ait olan $6-311 \mathrm{G}++(\mathrm{d}, \mathrm{p})$ optimize geometri kullanılarak şekil 3'de verilmiştir. MEP hesaplamaları B3LYP/YFK ve 6$311++(d, p)$ temel baz seti kullanılarak yapılmıştır. Diğer hesaplamalarda olduğu gibi etkileşimlerde çözücü etkisini gözlemleyebilmek için gaz faza ilave olarak üç farklı çözücü ile MEP haritaları belirlenmiş ve V(r) değerleri karşılaştırılmıştır. Gaz faza ait MEP haritası incelendiğinde en negatif bölgeler N1, $\mathrm{N} 2$ ve N3 atomları üzerine konumlanmış olup MEP değerleri sirasiyla $-0.05287,-0.06244$ ve -0.05886 a.b'dir. En pozitif bölgeler ise hidrojenler üzerinde olup en yüksek değer +0.03414 a.b değeriyle $\mathrm{C} 9$ atomuna bağlı hidrojen atomuna aittir.

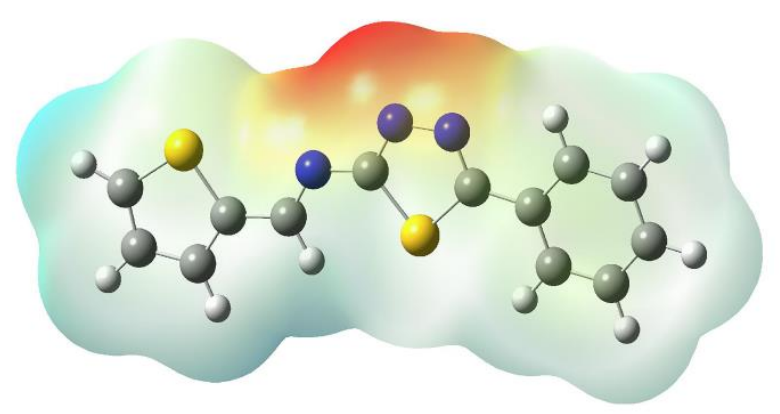

Şekil 3. (E)-5-Fenil-N-(2-tiyenillmetilen)-1,3,4-tiyadiazol-2amin bileşiğine ait MEP haritası.

Atomların sahip olduğu yük değerlerine bakıldığında sonuçlar tüm yöntemler için aynı atomlar üzerinde negatif olarak konumlandığı görülmekte olup böylelikle molekül için nükleofilik ve elektrofilik bölgeler belirlenmiştir. Bu durumda, sentezi yapılacak yeni moleküllerde tepkimenin nereden yürütülmesi gerektiğini önceden görmemize olanak sağlayacaktır. MEP haritasında ilave olarak ortamın çözücü etkisine bakıldığında ise genel olarak gaz fazının verilerini doğrulamakta yine en negatif bölgelerin nitrojen atomları üzerinde en pozitif bölgelerin ise hidrojenler üzerinde konumlandığı gözükmekte olup $\mathrm{V}(\mathrm{r})$ değerlerinin ise ortamın çözücülüğüne göre arttığı gözlenmektedir.

\subsection{Yük Analiz Bulguları}

Yük analiz metotları moleküler sisteme ait elektron yoğunluğunun atomlar arasında paylaşımını ve her bir atom üzerindeki yük miktarlarını bulmayı amaçlamaktadır. Mulliken yük analizinde (Mulliken, 1955), molekül üzerindeki toplam yük atomlar üzerine dağıtılmaktadır. Moleküle ait net yükler Mulliken ve Doğal yük analizi ile aynı yöntemler ile hesaplanmış ve sonuçlar Tablo 2'de karşılaştırılmıştır. Tablo 2 incelendiğinde her iki yöntemden de edilen net yük değerlerinin birbirleri ile uyum içinde oldukları görülmektedir. Doğal yük analizine göre en negatif yükler sirasıly $\mathrm{N} 3>\mathrm{N} 1>\mathrm{N} 2>\mathrm{C} 11>\mathrm{C} 10>\mathrm{C} 12>\mathrm{C} 4>>\mathrm{C} 2>\mathrm{C} 3>\mathrm{C} 1>\mathrm{C} 13>\mathrm{C} 5>\mathrm{C} 6$ olarak belirlenirken; Mulliken yüklerine göre siralama $\mathrm{C} 1>\mathrm{C} 10>\mathrm{C} 8>\mathrm{C} 1>\mathrm{C} 12>\mathrm{C} 10>\mathrm{C} 8>\mathrm{C} 4>\mathrm{S} 2>\mathrm{C} 3>\mathrm{S} 1 \quad$ olarak değişiklik göstermektedir. $\mathrm{Bu}$ değişikliğin temel sebebinin atomlar arasındaki elektronegatiflik farkı olarak değerlendirilebileceği yönünde görüş belirtilebilir. Yük miktarlarındaki değişikliğe çözücü ortamının etkisi ilave edildiğinde; ortamın çözücülüğü arttıkça genel olarak yük miktarlarındaki artışın göze çarptığı gözükmektedir. Sonuçların genel olarak MEP haritasındaki verileri desteklediği görülmesine rağmen diğer taraftan ilgili yöntemlerin yük miktarlarının dağılımında kullandıkları teoremler incelendiğinde sonuçların tahmini nitel değerleri verdiği de unutulmamalıdır. Diğer taraftan aynı çözücü ortamları ile moleküle ait Fukui fonksiyon analizleri yapılmış ve Tablo 3'te verilmiştir. Yük analizi sonucunda moleküle ait nükleofilik ve elektrofilik bölgeler belirlenmiştir. Tablo 3 incelendiğinde molekülde genel olarak nükleofilik yatkınlığın nitrojen atomları üzerinde olduğu, elektrofilik bölgenin sadece $\mathrm{S}$ atomları üzerinde yoğunlaştığ görülmektedir ve bu durum hem MEP haritalarından hem de yük analizlerinden elde ettiğimiz verileri destekler niteliktedir.

İlgili bölgeler belirlenirken molekülün nötr, anyonik ve katyonik durumlarına ait doğal yük analizleri yapılmaktadır. Eşitliklerde; $f_{k}^{+}(r)$ nükleofilik atağa yatkınlığı, $f_{k}^{-}(r)$ ise elektrofilik atağa yatkınlığı göstermektedir. Eşitliklerde kullanılan $q_{k}(r)$ atomik yükleri temsil ederken $\mathrm{N}$ (nötr), $\mathrm{N}+1$ (anyonik) ve N-1 ise (katyonik) kimyasal bölgelerdeki yükleri göstermektedir. Eğer $\Delta f(r)>0$ ise molekülde nükleofilik yatkınlık, $\Delta f(r)<0$ ise elektrofilik yatkınlık gözlenmektedir. Tablo 3 incelendiğinde molekülde genel olarak nükleofilik yatkınlığın baskın olduğu görülmektedir.

\subsection{Sinır Orbitalleri ve bunlardan türetilen kuantum kimyasal nicelikler}

Moleküler orbitallerde boş olan en düşük enerjili moleküler orbitale LUMO (Lowest Unoccupied Molecular Orbital), dolu olan en yüksek enerjili orbitalede HOMO (Highest Occupied Molecular Orbital) denilmektedir ki moleküller arasındaki kimyasal reaksiyonların açıklanmasında bu orbitaller kullanılmaktadır. HOMO ve LUMO aralığı küçüldükçe orbitallerin elektronları arasındaki etkileşim çok daha kolay olacaktır. Sınır orbitalleri adı da verilen bu orbitallerin enerjileri 
ve elektron yoğunluklarına bakılarak molekülün girebileceği reaksiyonlar hakkında da tahminler yapılabilir. Çünkü tüm reaksiyonlar bu iki orbital arasında gerçekleşmektedir. Hesaplamalar B3LYP Yoğunluk Fonksiyoneli Kuramı (YFK) 6$311++(d, p)$ temel baz seti kullanılarak yapılmış olup böylelikle molekülün en düşük enerjili durumuna ait mevcut elektron dağılımları çıkartılmış ve HOMO-LUMO şekillenimleri elde edilmiştir (Şekil 4). Elde edilen HOMO elektronlarının dağılımına bakıldığında elektron yoğunluğunun tüm molekül üzerinde dağıldığı, LUMO elektronlarında ise daha çok tiyofen ve tiyadiazol halkaları üzerinde toplandığı gözlenmektedir ve yük akışının da bu halkalara doğru olduğu açıkça gözükmektedir. Tablo 4' de ise molekülün sahip olduğu sınır orbitalleri ve bunlardan türetilmiş kuantum kimyasal nicelikler farklı çözücü ortamlarında hesaplanmıştır.

Tabloya göre ortamın çözücülüğü arttıkça HOMO-LUMO enerji düzeyleri arasındaki fark artmaktadır ve bu da kimyasal sertliğin artmasına yol açmaktadır. Kimyasal olarak sert atomlar yüksek iyonlaşma enerjisine sahip olup elektron ilgileri oldukça düşüktür. Yani enerji aralığı ne kadar küçükse birbirleri ile etkileşimleri o kadar kolay olacaktır. Kimyasal sertlik yük yoğunluğunun fazla olması, yumuşaklık ise az olmasıdır. Molekülün oldukça yüksek enerji aralığına sahip olmasından kaynaklı olarak yüksek kimyasal sertlik değerine sahip olduğu söylenebilir. Bunlara ek olarak elde edilen diğer kuantum kimyasal nicelikler ise Tablo 4'te verilmiştir.

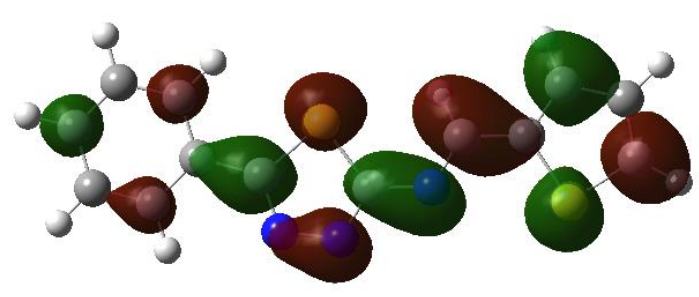

(LUMO)

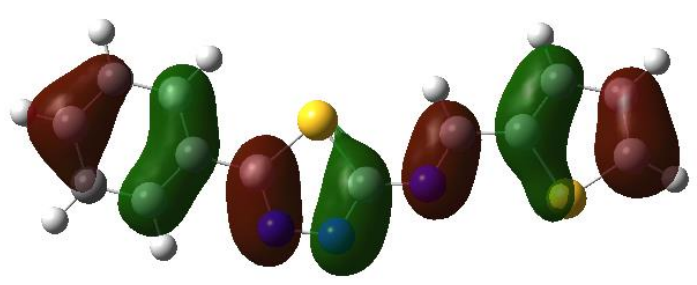

(HOMO)

Şekil 4. Molekülün HOMO ve LUMO şekillenimi.

\subsection{Hirshfeld Yüzey Analizi}

Moleküle ait Hirshfeld yüzey analizi ve 2D parmak izi haritası çalışmaları Crystal Explorer 3.1 programı ile gerçekleştirilmiştir (Wolff vd., 2012). Hirshfeld analizi moleküller arası etkileşmeleri araştırmak için kullanılır ve bunu Van der Waals mesafelerini görselleştirerek yapar. Diğer taraftan molekülde bulunan atomların birbirleri ile olan etkileşimlerini de 2D parmak izi analizi ile belirlemektedir. Bu analizde $d_{\text {norm }}$ en temel yüzey haritası olup beyaz, mavi ve kırmızı bölgelerden oluşur. $\mathrm{Bu}$ bölgelerden mavi olanlar Van der Waals yarıçapından daha büyük olan etkileşmeleri gösterirken, kırmızı olanlar Van der Waals yarıçapına yakın olanları gösterir. Molekül için $d_{\text {norm şekil }}$

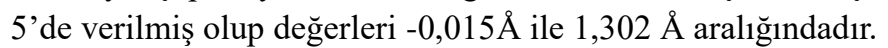

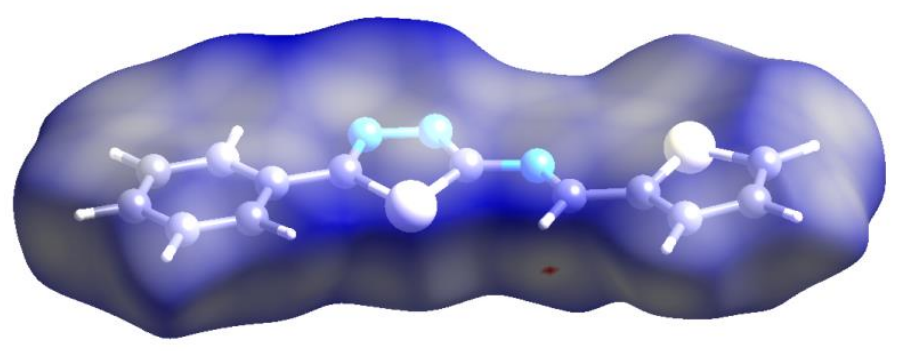

Şekil 5. Molekülün Hirshfeld Yüzey Analizi.

Molekülün Hirshfeld analizi incelendiğinde moleküller arası yüksek değerli bir etkileşimin olmadığı görülmektedir ki bu durum X-1şını kırınımı verilerinde de rapor edilmiştir (Demirtaş vd., 2009). 2D parmak izi analizine bakıldığında Hirshfeld yüzeyine en büyük katkılar $\% 30.4$ ile $\mathrm{H} \cdots \mathrm{H}$ etkileşiminden, $\% 21.8$ ile $\mathrm{N} \cdots \mathrm{H} / \mathrm{H} \cdots \mathrm{N}$ etkileşiminden ve $\% 16.3$ ile $\mathrm{C} \cdots \mathrm{H} / \mathrm{H} \cdots \mathrm{C}$ etkileşiminden gelmektedir. Hirshfeld yüzeyine katkısı olan baskın etkileşimlere ait 2D parmak izi haritaları Şekil 6'da verilmiştir.
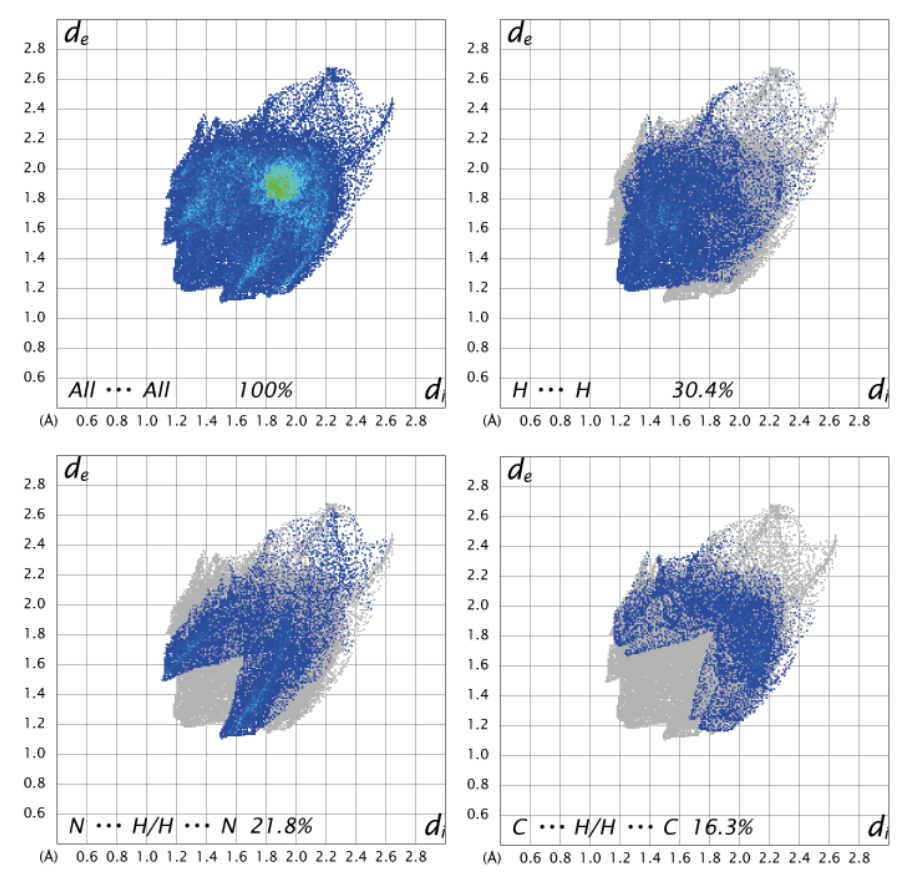

Şekil 6. Molekülün baskın olan etkileşmelerine ait 2D parmak izi haritas1. 
Tablo 2. Moleküle ait Mulliken ve Doğal popülasyon yük miktarları.

\begin{tabular}{|c|c|c|c|c|}
\hline$N P A$ & $\mathrm{gaz} / \mathcal{E}=1$ & etanol $/ \mathcal{E}=24.55$ & $d m s o / \mathcal{E}=46.7$ & $s u / \mathcal{E}=78.39$ \\
\hline $\mathrm{C} 1$ & -0.18245 & -0.18892 & -0.18906 & -0.18952 \\
\hline $\mathrm{C} 2$ & -0.19871 & -0.20691 & -0.20707 & -0.20758 \\
\hline $\mathrm{C} 3$ & -0.18809 & -0.19439 & -0.19457 & -0.19500 \\
\hline $\mathrm{C} 4$ & -0.19647 & -0.20688 & -0.20739 & -0.20792 \\
\hline $\mathrm{C} 5$ & -0.15978 & -0.17560 & -0.17636 & -0.17719 \\
\hline C6 & -0.09773 & -0.10895 & -0.10918 & -0.10931 \\
\hline $\mathrm{C} 7$ & 0.06630 & 0.06923 & 0.06923 & 0.06933 \\
\hline $\mathrm{C} 8$ & 0.21460 & 0.22112 & 0.22127 & 0.22107 \\
\hline C9 & 0.14210 & 0.14006 & 0.14125 & 0.14095 \\
\hline $\mathrm{C} 10$ & -0.28263 & -0.28014 & -0.28809 & -0.28044 \\
\hline $\mathrm{C} 11$ & -0.35454 & -0.34564 & -0.34473 & -0.34523 \\
\hline $\mathrm{C} 12$ & -0.26758 & -0.27116 & -0.27828 & -0.27173 \\
\hline $\mathrm{C} 13$ & -0.17921 & -0.18067 & -0.16492 & -0.17996 \\
\hline N1 & -0.27632 & -0.31781 & -0.31939 & -0.32138 \\
\hline N2 & -0.24846 & -0.32195 & -0.32478 & -0.32743 \\
\hline N3 & -0.45997 & -0.50623 & -0.50841 & -0.51192 \\
\hline $\mathrm{S} 1$ & 0.28170 & 0.34015 & 0.34249 & 0.34775 \\
\hline $\mathrm{S} 2$ & 0.48846 & 0.45968 & 0.45715 & 0.45639 \\
\hline \multicolumn{5}{|c|}{ Mulliken } \\
\hline $\mathrm{C} 1$ & -1.093888 & -0.974741 & -1.074673 & -0.963707 \\
\hline $\mathrm{C} 2$ & 0.184006 & 0.183244 & 0.184360 & 0.184782 \\
\hline $\mathrm{C} 3$ & -0.152639 & -0.14861 & -0.146378 & -0.143726 \\
\hline $\mathrm{C} 4$ & -0.281160 & -0.306848 & -0.225807 & 0.300251 \\
\hline $\mathrm{C} 5$ & 0.504582 & 0.680662 & 0.564668 & 0.679082 \\
\hline C6 & 0.887354 & 0.770565 & 0.741276 & 0.752087 \\
\hline $\mathrm{C} 7$ & 0.379537 & 0.307731 & 0.430327 & 0.306223 \\
\hline $\mathrm{C} 8$ & -0.551056 & -0.428582 & -0.427362 & -0.420837 \\
\hline C9 & -0.091606 & -0.141064 & -0.037588 & -0.128778 \\
\hline $\mathrm{C} 10$ & -0.596904 & -0.839494 & -0.630313 & -0.840731 \\
\hline $\mathrm{C} 11$ & 0.569895 & 0.696247 & 0.548701 & 0.694397 \\
\hline $\mathrm{C} 12$ & -0.851803 & -1.089409 & -0.833221 & -1.087917 \\
\hline $\mathrm{C} 13$ & 1.230015 & 1.726470 & 1.281231 & 1.725185 \\
\hline N1 & 0.005253 & -0.046156 & -0.058089 & -0.052553 \\
\hline N2 & 0.030092 & -0.099485 & -0.104975 & -0.108678 \\
\hline N3 & 0.219026 & 0.139453 & -0.130637 & 0.130777 \\
\hline $\mathrm{S} 1$ & -0.117074 & -0.102968 & -0.060118 & -0.095995 \\
\hline $\mathrm{S} 2$ & -0.273628 & -0.329764 & -0.282678 & -0.329361 \\
\hline
\end{tabular}


Tablo 3. NPA yüklerinden elde edilmiş Fukui Fonksiyon Analizi.

\begin{tabular}{lllllll} 
& $\boldsymbol{q}^{\boldsymbol{0}}$ & $\boldsymbol{q}^{+}$ & $\boldsymbol{q}^{-}$ & $\boldsymbol{f}^{+}$ & $\boldsymbol{f}^{-}$ & $\Delta \boldsymbol{f}(\boldsymbol{r})$ \\
\hline C1 & -0.18245 & -0.05908 & -0.21788 & 0.12337 & 0.03543 & 0.08794 \\
C2 & -0.19871 & -0.08790 & -0.20668 & 0.11081 & 0.00797 & 0.10284 \\
C3 & -0.18809 & 0.01718 & -0.25030 & 0.20527 & 0.06221 & 0.14306 \\
C4 & -0.19647 & -0.11039 & -0.21023 & 0.08608 & 0.01376 & 0.07232 \\
C5 & -0.15978 & -0.02008 & -0.19134 & 0.1397 & 0.03156 & 0.10814 \\
C6 & -0.09773 & -0.00262 & -0.07630 & 0.09511 & -0.02143 & 0.11654 \\
C7 & 0.06630 & 0.09013 & -0.01437 & 0.02383 & -0.08067 & 0.10450 \\
C8 & 0.21460 & 0.15417 & 0.20507 & -0.06043 & 0.00953 & 0.05090 \\
C9 & 0.14210 & 0.08296 & -0.00715 & -0.05914 & 0.14925 & -0.20839 \\
C10 & -0.28263 & -0.06778 & -0.24848 & 0.21485 & 0.16526 & 0.04959 \\
C11 & -0.35454 & -0.05795 & -0.44789 & 0.29659 & 0.09335 & 0.20839 \\
C12 & -0.26758 & -0.10664 & -0.27345 & 0.16094 & 0.00587 & 0.15507 \\
C13 & -0.17921 & -0.04081 & -0.27263 & 0.1384 & 0.09342 & 0.04498 \\
N1 & -0.27632 & -0.04966 & -0.29396 & 0.22666 & 0.01764 & 0.20902 \\
N2 & -0.24846 & -0.02731 & -0.31541 & 0.22115 & 0.06695 & 0.15420 \\
N3 & -0.45997 & -0.16002 & -0.51012 & 0.29995 & 0.05015 & 0.24980 \\
S1 & 0.28170 & 0.15744 & 0.18433 & -0.12426 & 0.09737 & 0.22163 \\
S2 & 0.48846 & 0.26149 & 0.39821 & -0.22697 & 0.09025 & 0.31722 \\
\hline$f_{k}^{+}(r)=q_{k}(r)(N+1)-q_{k}(r)(N) ; f_{k}^{-}(r)=q_{k}(r)(N)-q_{k}(r)(N-1) ; \Delta f_{k}(r)=\left[f_{k}^{+}(r)-f_{k}^{-}(r)\right]$
\end{tabular}

Tablo 4. Moleküle ait farklı baz setleri kullanılarak hesaplanmış kuantum kimyasal parametreler.

\begin{tabular}{|c|c|c|c|c|}
\hline B3LYP & $g a z / \mathcal{E}=1$ & etanol $/ \mathcal{E}=24.55$ & $d m s o / \mathcal{E}=46.7$ & $s u / \mathcal{E}=78.39$ \\
\hline Toplam enerji & -1461.61001011 & -1461.63295673 & -1461.63383239 & -1461.6349785 \\
\hline İyonizasyon enerjisi,I & 6.3237 & 6.4869 & 6.3688 & 6.3634 \\
\hline Elektron ilgisi, A & 2.8618 & 2.8561 & 2.8607 & 2.8540 \\
\hline Enerji aralı̆ $\breve{1}, \Delta E$ & 3.4618 & 3.6308 & 3.5081 & 3.5114 \\
\hline Elektronegatiflik, $\chi$ & 4.5927 & 4.6715 & 4.6147 & 4.6077 \\
\hline Kimyasal sertlik, $\eta$ & 1.7309 & 1.8154 & 1.7540 & 1.7557 \\
\hline Kimyasal yumuşaklık, $S$ & 0.5777 & 0.5508 & 0.5701 & 0.5695 \\
\hline Elektrofilik indeks, $\omega$ & -12.1860 & -12.0209 & -12.1410 & -12.0925 \\
\hline
\end{tabular}

\section{Sonuç}

Sonuç olarak (E)-5-Fenil-N-(2-tiyenillmetilen)-1,3,4tiyadiazol-2-amin molekülüne ait moleküler yapı, elektronik ve kimyasal özellikler deneysel (Demirtaş vd., 2009) ve kuantum mekaniksel hesaplama yöntemleriyle araştırılmış ve sonuçlar e-ISSN: 2148-2683 karşılaştırılıp, tartışılmıştır. Deneysel ve teorik değerlerin genel olarak uyum içerisinde olduğu gözlenmiş olup KOK değerleri gaz ve diğer çözücüler için (etanol, dmso ve su) sirasiyla 0.0210 , $0.0316,0.0261$ ve 0.0193 (bağ uzunluğu); 1.0439, 1.0732, 1.1076 ve 1.0363 (bağ açısı) olarak bulunmuştur. Sonuçlara bakıldığında gaz fazdan uzaklaşıldıkça deneysel değerlerden 
uzaklaşıldığı ve ortamın polaritesine bağlı olarak geometrik parametrelerde artışın olduğu gözlenmektedir. Diğer taraftan moleküllerin MEP haritaları incelendiğinde, en negatif bölgeler $\mathrm{N}$ gibi elektronegatifliği yüksek olan atomlar üzerinde, en pozitif bölgeler ise $\mathrm{H}$ atomları üzerinde gözlenmiştir. Moleküllerin Mulliken yük dağılımlarına ve Fukui fonksiyon analizlerine bakıldığında MEP haritaları ile oldukça uyum içinde oldukları gözlenmektedir.

\section{Teşekkür}

$\mathrm{Bu}$ çalışmanın yazarları olarak herhangi bir destek ve teşekkür beyanımızın olmadığını bildiririz.

\section{Kaynakça}

Cordell, G. A. (2008). The alkaloids: chemistry and biology. Academic Press.

Çırdakl1, D., (2018). Bazı n-(4-sübstitüebenziliden)-5-fenil 1,3,4-tiyadiazol-2-amin türevleri üzerinde çalışmalar, Hacettepe Üniversitesi, Sağlık Bilimleri Enstitüsü, Yüksek Lisans Tezi, 2018.

Demirtaş G., Dege N., Şekerci M., Servi S., Dinçer M., Acta Cryst. (2009). E65, o1668.

Dennigton R. II, T. Keith, J. Millam, GaussView, Version 4.1.2, Semichem, Inc., (2007), Shawnee Mission, KS.

French, L. (2005). Dysmenorrhea. American family physician, $71(2)$.

Frisch M. J. et al., Gaussian 03, Revision E.01, Gaussian, Inc., (2004), Wallingford CT.

Hagar, M., Ahmed, H. A., Aljohani, G., \& Alhaddad, O. A. (2020). Investigation of some antiviral N-heterocycles as COVID 19 drug: Molecular docking and DFT calculations. International Journal of Molecular Sciences, 21(11), 3922.

Mulliken, R. S., Electronic Population Analysis on LCAO-MO Molecular Wave Functions. I. (1955) J. Chem. Phys., 23, 1833-1840.

Özdemir Tarı, G., (2013). Schiff Bazı İçeren Bazı Organik Moleküllerin Deneysel ve Teorik Olarak İncelenmesi, Doktora Tezi. Ondokuz Mayıs Üniversitesi, Fen Bilimleri Enstitüsü, Samsun.

Rossi, S. (2013). Adelaide: The Australian Medicines Handbook Unit Trust. Antimycotic imidazoles. part, 4.

Shihab S.A. B. , (2021). 1,3,4-tiyadiazol bileşiklerinden elde edilen yeni azo boyarmaddelerin sentezi ve absorpsiyon özelliklerinin incelenmesi, Kastamonu Üniversitesi, Fen Bilimleri Enstitüsü Yüksek Lisans Tezi, Kastamonu.

Wolff D. S. K., Grimwood D. J., McKinnon J. J., Turner M. J. and Spackman M.A an J., Crystal Explorer (Version 3.1), Univ. West. Aust. (2012). https://doi.org/10.1039/b704980c. 